\title{
Tissue plasminogen activator versus heparin for locking dialysis catheters: A systematic review
}

\author{
Belal M. Firwana, Rim Hasan, Mazen Ferwana ${ }^{1}$, Joseph Varon², Aaron Stern³, Umesh Gidwani
}

Department of Medicine, University of Damascus, Damascus, Syria, ${ }^{1}$ King Saud Bin Abdulaziz University for Health Sciences, Riyadh, Kingdom of Saudi Arabia, ${ }^{2}$ The University of Texas Health Science at Houston, Houston, Texas, ${ }^{3}$ Division of Nephrology, Elmhurst Hospital Center, New York, ${ }^{4}$ Cardiovascular Institute, Mount Sinai Medical Center, New York, USA

\begin{tabular}{|c|}
\hline Access this article online \\
\hline Website: www.avicennajmed.com \\
\hline DOI: 10.4103/2231-0770.90913 \\
\hline Quick Response Code: \\
\hline
\end{tabular}

\begin{abstract}
Background and Objectives: Hemodialysis catheters are commonly used when renal replacement therapy is initiated. These catheters have significant complications. Among "locking" solutions used in an attempt to decrease these complications is recombinant tissue plasminogen activator (rt-PA). This systematic review is to determine the efficacy of rt-PA versus heparin, the standard of care. Materials and Methods: A systematic review of randomized controlled trials studying rt-PA alone or rt-PA plus heparin versus heparin alone as locking agents for hemodialysis catheters, which included patients needed a temporary hemodialysis catheter for hemodialysis. We identified relevant trials through electronic databases and correspondence with experts. Two investigators independently reviewed potentially eligible trials and extracted data. Results: Three trials met the inclusion criteria. One trial reported an improved catheter malfunctioning in patients using rt-PA plus heparin to lock catheters $(20.0 \%)$ versus heparin alone $(34.8 \%)$. Another trial reported higher blood flow rate in hemodialysis catheters in patients who received rt-PA $(231.6 \pm 12.4 \mathrm{~mL} / \mathrm{min})$ compared with those who received heparin $(206.9$ $\mathrm{mL} / \mathrm{min}$ ). The third trial reported formation and weight of clots which were decreased by half in rt-PA group versus heparin group. Conclusions: In the few randomized trials that met our inclusion criteria, the use of rt-PA as a locking solution for hemodialysis catheters seems to be associated with fewer adverse events and catheter malfunctioning as compared with heparin. Our systematic review is limited by the few randomized trials addressing our question and the wide variety of outcome measures. Further prospective randomized trials are needed to confirm this conclusion.
\end{abstract}

Key words: Anticoagulants, catheter, dialysis, hemodialysis, heparin, prophylaxis, tissue plasminogen activator

\section{INTRODUCTION}

Among patients with end-stage kidney disease in the United States who undergo hemodialysis for renal replacement and to continue filtering the blood, $82 \%$ started their hemodialysis with a catheter. ${ }^{[1]}$ Of these catheters, $25 \%-$ $50 \%$ fail within the first year of insertion. ${ }^{[2-4]}$ Most of these failures are related directly to either thrombosis or infection. ${ }^{[5]}$ Infection risks include local catheter site infection and systemic bacteremia, which both require prompt removal of the catheter and appropriate intravenous antibiotic therapy. ${ }^{[6,7]}$ Thrombosis, on the other hand, accounts for $10 \%-42 \%$ of catheter malfunctioning depending on catheter site; ${ }^{[8]}$ for which thrombolytic agents, such as recombinant tissue plasminogen activator (rt-PA), are effective. ${ }^{[9]}$ Heparin is routinely used as a "locking" solution for preventing thrombosis-related catheter malfunction. ${ }^{[10]}$ Other agents, such as warfarin, ${ }^{[11]}$ sodium citrate, ${ }^{[12,13]}$ and low-molecular weight heparin, ${ }^{[14]}$ have been studied for the same purpose.

rt-PA was first used as a prophylaxis in oncology patients with central venous catheters. ${ }^{[15,16]}$ In small, randomized clinical trials, this agent was also studied as a locking

Address for correspondence: Prof. Umesh K. Gidwani, Mount Sinai Medical Center, Director of Cardiac Critical Care, Cardiovascular Institute (Box 1030), One Gustave L. Levy Place, New York, NY 10029, USA. E-mail: umesh.gidwani@mountsinai.org 
solution for hemodialysis catheters, ${ }^{[17]}$ and more recently in large and powered trials. ${ }^{[18,19]}$ These studies showed significantly better outcomes with rt-PA than comparator solutions. In this systematic review, we summarized data on effectiveness reported in all published randomized control trials comparing rt-PA versus heparin as locking agents for hemodialysis catheters.

\section{MATERIALS AND METHODS}

\section{Eligibility criteria}

Studies that enrolled patients with end-stage renal disease who needed dialysis, using a hemodialysis catheter and allocated them at random either to rt-PA alone or rt-PA plus heparin versus heparin, using them as locking solutions, were eligible for review. Studies using rt-PA plus heparin versus heparin were considered eligible. Studies were included regardless of the size or language of publication. Observational studies were excluded. Cointerventions with any other anticoagulant were excluded. Due to limited studies available, we accepted all outcome measures reported to widen the findings of our search.

\section{Information sources and search methods}

A comprehensive literature search of electronic databases (MEDLINEÔ, EMBASE, and the Cochrane Library) was conducted, irrespective of the date of publication using the appropriate terms and text words. Key words used to buildup the search strategy were "tissue plasminogen activator," "heparin," and "catheter." The authors determined trial eligibility and extracted descriptive, methodologic, and outcome data from each eligible randomized controlled trial.

\section{Selection of studies}

Two authors (Firwana and Hasan) independently identified trials for inclusion. Initially, titles and abstracts of the records retrieved by the search were assessed in order to exclude those that were irrelevant. For the remaining records, fulltext articles were retrieved and assessed in order to select trials that meet the inclusion criteria.

\section{Control of bias assessment}

Methodological quality was defined as the control of bias assessed through the reported methods in each individual trial. ${ }^{[20]}$ Two reviewers independently assessed trial quality by examining three components: generation of allocation sequence (classified as adequate if based on computergenerated random numbers, tables of random numbers, or similar), concealment of allocation (classified as adequate if based on central randomization, sealed envelopes, or similar), and blinding (classified as adequate if the trial was described as double blind or had blinded outcome assessment). Disagreements between the reviewers were resolved by arbitration by a third author (Ferwana).

\section{Data collection and extraction}

This study was performed in accordance with the recommendations set forth by the Preferred Reporting Items for Systematic Reviews and Meta-Analyses (PRISMA). ${ }^{[21]}$ Two reviewers extracted data from identified trials (Firwana and Hasan). We extracted prespecified data elements from each trial, including study design, agent used for locking hemodialysis catheter, baseline characteristics, sample size, outcome measures, period of the study, and other study characteristics. The number of events in each trial was extracted on the basis of the intention-to-treat approach.

\section{Statistical analysis and measures of treatment effect}

Our purpose was to perform a meta-analysis to assess relative risks to measure the effectiveness and harmfulness measures for hemodialysis catheters prophylaxis with rt$\mathrm{PA}, \mathrm{I}^{2}$ statistics for heterogeneity of treatment effects, and subgroup analyses to adjust for different variables. Due to limited number of available studies and data availability on one hand, and due to both heterogenous outcome measures and different types of data represented on the other hand, the applicability of conducting pooled analyses and forest plots in this review was limited. There was no one similar outcome in at least two trials to combine the results. In one study, dichotomous results were reported, another study reported continuous data, and the last study reported odds ratios (ORs) only without providing detailed results for both study arms. Corresponding authors were contacted, with no additional data provided. Available raw data are obtained; the OR with $95 \%$ confidence intervals (CIs) was calculated for dichotomous data, mean differences (MDs) with 95\% CI were calculated for continuous data. Analyses were conducted using features on RevMan version 5.0 (The Nordic Cochrane Center, Copenhagen, Denmark). We therefore used this systematic review to summarize available data in included trials assessing the use of rt-PA versus heparin as locking agents in hemodialysis catheter.

\section{RESULTS}

\section{Selection and description of enrolled studies}

The original search identified 122 potentially eligible citations, of which only 3 randomized trials were identified ${ }^{[17,18,22]}$ [Figure 1], with a total of 246 studied participants [Table 1]. The enrolled patients in two of the studies were adult patients, with a mean age of more than 60 years; the third study had a pediatric population. Two of these studies were performed in Europe, while the third randomized trial was performed in Canada. Both Gittins et al. and 


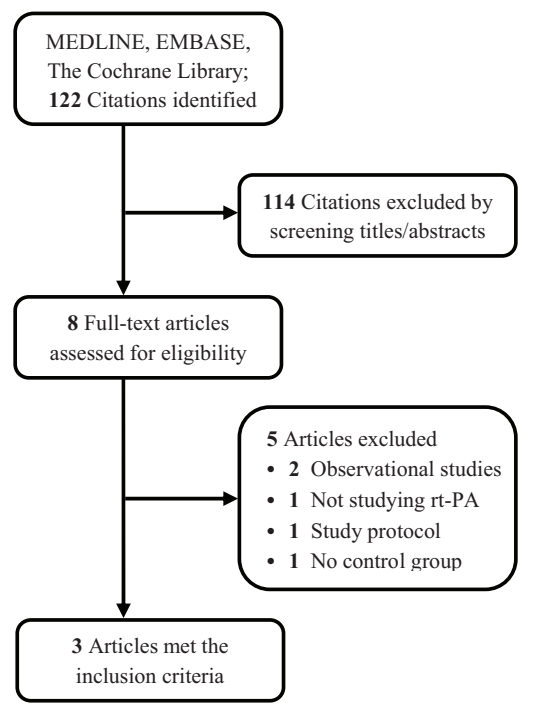

Figure 1: Flow chart of the systematic review

Schenk et al. compared rt-PA with heparin in a cross-over design, reporting the overall outcomes at the end of the two cross-over phases. Hemmelgarn et al. followed two treatment arms to the end the study period; one arm was getting rt-PA flushing once weekly plus heparin flushing twice weekly to lock catheters, where the other arm was receiving heparin alone thrice weekly.

In Hemmelgarn et al., one outcome measure was hemodialysis catheter malfunction, which was defined as the first occurrence of any one of the following: inability to initiate dialysis owing to inadequate blood flow, mean blood flow of $250 \mathrm{~mL} / \mathrm{min}$ or less during two consecutive dialysis treatments, or peak blood flow of $200 \mathrm{~mL} / \mathrm{min}$ or less for 30 minutes during a dialysis treatment; and another outcome measure was catheter-related bacteremia. In Schenk et al., outcome measures were mean blood flow rate, mean venous pressure, and arterial pressure. Gittins et al. reported on the weight of blood clot aspirated from the line at the start of the next dialysis session. The follow-up time assigned to complete each study, including both crossed arms, ranged from 10 weeks to 8 months [Table 1].

\section{Risk of bias within studies}

Regarding the methodological quality of these three studies, Hemmelgarn et al. described a well-conducted methodology, clear randomization, and blinding; the other two studies mentioned their studies to be randomized, but the methods for randomization or concealment were not specified. There was no early termination in either study due to study protocol. Funding sources were clear in two of the three studies [Table 1].

None of trials included reported on mortality or quality of life; this could be associated with the relatively short duration

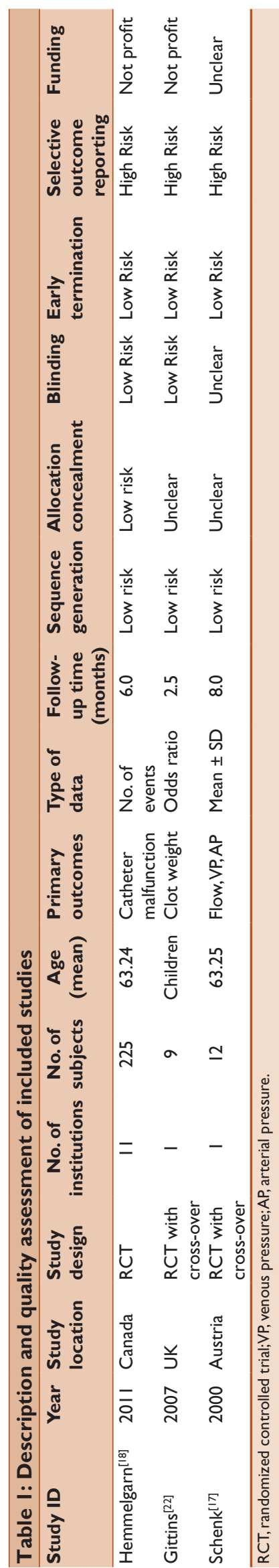




\begin{tabular}{|c|c|c|c|c|}
\hline & rt-PA $(n=110)$ & Heparin $(n=115)$ & Odds ratio & $95 \% \mathrm{Cl}$ \\
\hline Catheter malfunction & $22(20.0 \%)$ & 40 (34.8\%) & 0.47 & $0.26-0.86$ \\
\hline Catheter-related bacteremia & $5(4.5 \%)$ & $15(13.0 \%)$ & 0.32 & $0.11-0.91$ \\
\hline
\end{tabular}

\begin{tabular}{lcccc}
\hline \multicolumn{1}{l}{ Table 3: Primary outcomes in Schenk et al. } & & & \\
& rt-PA $(\boldsymbol{n}=1 \mathbf{0})$ & Heparin $(\boldsymbol{n}=1 \mathbf{0})$ & Mean difference & $\mathbf{9 5 \%} \mathbf{C l}$ \\
\hline Blood flow rate $(\mathrm{mL} / \mathrm{min})$ & $231.6 \pm 12.4$ & $206.9 \pm 14.2$ & 25.60 & $\mid 4.93-36.27$ \\
Venous pressure $(\mathrm{mmHg})$ & $140 \pm 15.2$ & $159.2 \pm 20.7$ & -19.20 & $-33.73--4.67$ \\
Arterial pressure $(\mathrm{mmHg})$ & $-\mid 15.9 \pm 12.7$ & $-134.7 \pm 25.8$ & 18.80 & $2.53-35.07$ \\
\hline
\end{tabular}

Catheters and ports dysfunction is defined as failure to attain and maintain an extracorporeal blood flow of $300 \mathrm{~mL} / \mathrm{min}$ or greater at a prepump arterial pressure more negative than $-250 \mathrm{~mm} \mathrm{Hg}$; the exception is pediatric or smaller adult catheters that are not designed to have flows in excess of $300 \mathrm{~mL} / \mathrm{min}{ }^{23}$

\begin{tabular}{|c|c|c|}
\hline & Odds ratio & $95 \% \mathrm{Cl}$ \\
\hline Clot formation* & 0.42 & $0.25-0.71$ \\
\hline Aspirate clot weight* & 0.53 & $0.42-0.67$ \\
\hline
\end{tabular}

of follow-up. These outcomes are long-term outcomes, and the maximum period of follow-up among included trials was 8 months.

\section{Tissue plasminogen activator effects \\ Catheter malfunction and blood flow rate}

Both Schenk et al. and Hemmelgarn et al. reported on blood flow. Hemmelgarn et al. used blood flow rates as a criterion to detect their primary outcome, catheter malfunctioning (see above); where Schenk et al. reported the mean flow rates in both groups. In Hemmelgarn et al., only 22/110 (20.0\%) patients of the rt-PA group developed catheter malfunction, whereas that number was $40 / 115$ (34.8\%) in the heparin group; a reduction of risk by $47 \%$ (95\% CI [26\%-86\%]) [Table 2].

Schenk et al. reported on mean blood flow rates and related venous and arterial pressures after using rt-PA and heparin for locking hemodialysis access. ${ }^{[17]}$ The rate of blood flow in the rt-PA group was $231.6 \pm 12.4 \mathrm{~mL} / \mathrm{min}$, whereas the rate of blood flow was $206.9 \pm 14.2 \mathrm{~mL} / \mathrm{min}$, giving significantly higher rates of blood flow using rt-PA than using heparin as a locking agent, with a MD of 25.60 (95\% CI 14.93-36.27). By the same measures, rt-PA-locked dialysis catheters causes significantly lower both venous pressure and arterial pressure $(140 \pm 15.2 \mathrm{mmHg}$ and $115.9 \pm 12.7$ $\mathrm{mmHg}$, respectively) when compared with heparin-locked catheters $(159.2 \pm 20.7 \mathrm{mmHg}$ and $134.7 \pm 25.8 \mathrm{mmHg})$; $(\mathrm{MD}=-19.20 ; 95 \% \mathrm{CI}-33.73$ to -4.67 and $\mathrm{MD}=18.80$; 95\% CI 2.53 to 35.07 , for venous and arterial blood flow, respectively) [Table 3]. Although mean blood flow rate was significantly better among patients on rt-PA than on heparin, worth noting that both of these blood flow rates are considered inadequate by standards for adult patients with end-stage kidney disease. ${ }^{[23]}$

\section{Catheter-related infection}

Only Hemmelgarn et al. reported on hemodialysis catheterrelated bacteremia. Results showed that bacteremia had developed in 5/110 (4.5\%) cases in the rt-PA group versus $15 / 115(13.0 \%)$ cases in the heparin group, decreasing the risk of catheter-related bacteremia by $32 \%$ (95\% CI [11\%91\%]) [Table 2]. Schenk et al. reported on patients who developed local infection at catheter site, which was only one patient while he was on heparin; none of the patients developed either local infection of bacteremia while treated with rt-PA.

\section{Clot weight and clot formation}

Both Gittins et al. and Schenk et al. reported on clot formation, where only Gittins et al. looked at weight of aspirated clot in addition. ${ }^{[22]}$ In Gittins et al., available numbers show that children who received rt-PA in their dialysis catheters formed $42 \%$ fewer clots than children who received heparin; in addition, the weight of formed clots (rtPA: $15 \mathrm{mg}$, heparin: $31 \mathrm{mg}$ ) was $16 \mathrm{mg}(53 \%)$ lighter in the rt-PA group compared with the heparin group. We could not retrieve raw number of events to calculate significance [Table 4].

Schenk et al. reported that none of the patients had clots while on the rt-PA group, where clotting occurred in $20 \%$ of the patients in the heparin period. In patients with clotting formation, fibrinolysis with intracatheter $2 \mathrm{mg}$ of $\mathrm{rt}-\mathrm{PA}$ was necessary and was only needed in the heparin group.

\section{DISCUSSION}

Although all available data showed superiority for rt-PA over heparin, the overall results are not convincing; due to the small number of conducted randomized trials studying rtPA versus heparin as locking solutions for dialysis catheters, the small number of participants in some of the conducted 
studies, and the limited sources of homogenous data and point estimates among studies, we could not perform a meta-analysis combining homogenous data together to get pooled results to predict effectiveness. Given these limitations, we reported primary outcomes from each individual study, and reanalyzed them separately, to obtain an estimate of rt-PA effectiveness.

The use of heparin as a locking solution has been the standard of care in this era due to its efficacy, reasonable side effect profile, and cost-effectiveness. ${ }^{[24,25]}$ In studies that used large central venous catheters for dialysis, heparin was shown to be superior to normal saline when used as a flush in dialysis catheters, keeping them more patent, decreasing the need of rt-PA to lyse formed clots within catheters, and improving catheter survival. ${ }^{[25-29]}$ Conversely, some other studies showed that heparin flushed not to be different from normal saline; not to increase the duration of catheter use or to improve its functionality and may prolong aPTT significantly; ${ }^{[29,30]}$ worth noting that these studies used smaller catheters either in peripheral intravenous catheters in children or as arterial catheters.

Clearly, in all enrolled studies, rt-PA was superior to heparin in all reported outcomes. The use of rt-PA reduced rates of developing malfunctioning in catheters locked with it; reduced rates of catheter-related bacteremia; provided good blood flow through catheters; and warrantees a better management for both venous and arterial pressures. Its use is also accompanied with less clot formation and less weight of these clots. ${ }^{[22]}$

The increased cost of using rt-PA could be one of the limitations in this largely Medicare population. Using rt-PA either every time or even once a week in a three-day week dialysis, rt-PA has been shown to be at least eight to nine times more expensive than using heparin three times a week. ${ }^{[17,18]}$ However, as suggested by Hemmelgarn et al., rt-PA may turn out to be cost-effective due to significantly decreased catheter malfunction and catheter-related bacteremia, fewer episodes of hospitalizations, and less serious adverse events without an increased incidence of major bleeding.

\section{CONCLUSION}

This systematic review shows that using rt-PA as a locking solution for hemodialysis catheters significantly reduces catheter-related bacteremia and catheter malfunctioning, improves venous and arterial blood flows, and is associated with less clot formation as compared with heparin; although the evidence is not convincing. Cost-effectiveness may be an issue for locking hemodialysis catheters with rt-PA. A need for adequately powered and long-term conducted randomized clinical trials to support or change the current results and knowledge of the effects of rt-PA for locking hemodialysis catheters still exists.

\section{REFERENCES}

1. Collins AJ, Foley RN, Gilbertson DT, Chen SC. The state of chronic kidney disease, ESRD, and morbidity and mortality in the first year of dialysis. Clin J Am Soc Nephrol 2009;4 Suppl 1:S5-11.

2. Allon M. Dialysis catheter-related bacteremia: Treatment and prophylaxis. Am J Kidney Dis 2004;44:779-91.

3. Duncan ND, Singh S, Cairns TD, Clark M, El-Tayar A, Griffith M, et al. Tesio-Caths provide effective and safe long-term vascular access. Nephrol Dial Transplant 2004;19:2816-22.

4. Suhocki PV, Conlon PJ Jr, Knelson MH, Harland R, Schwab SJ. Silastic cuffed catheters for hemodialysis vascular access: Thrombolytic and mechanical correction of malfunction. Am J Kidney Dis 1996;28:379-86.

5. Klouche K, Amigues L, Deleuze S, Beraud JJ, Canaud B. Complications, effects on dialysis dose, and survival of tunneled femoral dialysis catheters in acute renal failure. Am J Kidney Dis 2007;49:99-108.

6. Ishani A, Collins AJ, Herzog CA, Foley RN. Septicemia, access and cardiovascular disease in dialysis patients: The USRDS Wave 2 study. Kidney Int 2005;68:311-8.

7. Oliver MJ, Callery SM, Thorpe KE, Schwab SJ, Churchill DN. Risk of bacteremia from temporary hemodialysis catheters by site of insertion and duration of use: A prospective study. Kidney Int 2000;58:2543-5.

8. Schillinger F, Schillinger D, Montagnac R, Milcent T. Post catheterisation vein stenosis in haemodialysis: Comparative angiographic study of 50 subclavian and 50 internal jugular accesses. Nephrol Dial Transplant 1991;6:722-4.

9. Daeihagh P, Jordan J, Chen J, Rocco M. Efficacy of tissue plasminogen activator administration on patency of hemodialysis access catheters. Am J Kidney Dis 2000;36:75-9.

10. Mojibian H, Spector M, Ni N, Eliseo D, Pollak J, Tal M. Initial clinical experience with a new heparin-coated chronic hemodialysis catheter. Hemodial Int 2009;13:329-34.

11. Willms L, Vercaigne LM. Does warfarin safely prevent clotting of hemodialysis catheters? A review of efficacy and safety. Semin Dial 2008;21:71-7.

12. Pierce DA, Rocco MV. Trisodium citrate: An alternative to unfractionated heparin for hemodialysis catheter dwells. Pharmacotherapy 2010;30:1150-8.

13. Power A, Duncan N, Singh SK, Brown W, Dalby E, Edwards C, et al. Sodium citrate versus heparin catheter locks for cuffed central venous catheters: A single-center randomized controlled trial. Am J Kidney Dis 2009;53:1034-41.

14. Malo J, Jolicoeur C, Theriault F, Lachaine J, Senecal L. Comparison between standard heparin and tinzaparin for haemodialysis catheter lock. ASAIO J 2010;56:42-7.

15. Chesler L, Feusner JH. Use of tissue plasminogen activator (rrt-PA) in young children with cancer and dysfunctional central venous catheters. J Pediatr Hematol Oncol 2002;24:653-6.

16. Blaney M, Shen V, Kerner JA, Jacobs BR, Gray S, Armfield J, et al. CAPS Investigators. Alteplase for the treatment of central venous catheter occlusion in children: Results of a prospective, open-label, singlearm study (The Cathflo Activase Pediatric Study). J Vasc Interv Radiol 2006;17:1745-51.

17. Schenk P, Rosenkranz AR, Wolfl G, Horl WH, Traindl O. Recombinant tissue plasminogen activator is a useful alternative to heparin in priming quinton permcath. Am J Kidney Dis 2000;35:130-6.

18. Hemmelgarn BR, Moist LM, Lok CE, Tonelli M, Manns BJ, Holden RM, et al. Prevention of Dialysis Catheter Lumen Occlusion with 
rt-PA versus Heparin Study Group. Prevention of dialysis catheter malfunction with recombinant tissue plasminogen activator. $\mathrm{N}$ Engl J Med 2011;364:303-12.

19. Tumlin J, Goldman J, Spiegel DM, Roer D, Ntoso KA, Blaney M, et al. A phase III, randomized, double-blind, placebo-controlled study of tenecteplase for improvement of hemodialysis catheter function: TROPICS 3. Clin J Am Soc Nephrol 2010;5:631-6.

20. Gluud LL. Bias in clinical intervention research. Am J Epidemiol 2006;163:493-501.

21. Liberati A, Altman DG, Tetzlaff J, Mulrow C, Gøtzsche PC, Ioannidis JP, et al. The PRISMA statement for reporting systematic reviews and metaanalyses of studies that evaluate health care interventions: Explanation and elaboration. J Clin Epidemiol 2009;62:e1-34.

22. Gittins NS, Hunter-Blair YL, Matthews JN, Coulthard MG. Comparison of alteplase and heparin in maintaining the patency of paediatric central venous haemodialysis lines: A randomised controlled trial. Arch Dis Child 2007;92:499-501.

23. Vascular Access Work Group. Clinical practice guidelines for vascular access. Am J Kidney Dis 2006;48 Suppl 1:S248-73.

24. Pettigrew M, Soltys GI, Bell RZ, Daniel N, Davis JR, Senecal L, et al. Tinzaparin reduces health care resource use for anticoagulation in hemodialysis. Hemodial Int 2011;15:273-9.

25. Ouseph R, Ward RA. Anticoagulation for intermittent hemodialysis.
Semin Dial 2000;13:181-7.

26. Davenport A. Review article: Low-molecular-weight heparin as an alternative anticoagulant to unfractionated heparin for routine outpatient haemodialysis treatments. Nephrology (Carlton) 2009;14:455-61.

27. Suranyi M, Chow JS. Review: Anticoagulation for haemodialysis. Nephrology (Carlton) 2010;15:386-92.

28. Jonker MA, Osterby KR, Vermeulen LC, Kleppin SM, Kudsk KA. Does low-dose heparin maintain central venous access device patency? A comparison of heparin versus saline during a period of heparin shortage. JPEN J Parenter Enteral Nutr 2010;34:444-9.

29. Del Cotillo M, Grane N, Llavore M, Quintana S. Heparinized solution vs. saline solution in the maintenance of arterial catheters: A double blind randomized clinical trial. Intensive Care Med 2008;34:339-43.

30. Mok E, Kwong TK, Chan MF. A randomized controlled trial for maintaining peripheral intravenous lock in children. Int J Nurs Pract 2007;13:33-45.

Cite this article as: Firwana BM, Hasan R, Ferwana M, Varon J, Stern A, Gidwani U. Tissue plasminogen activator versus heparin for locking dialysis catheters: A systematic review. Avicenna J Med 2011;1:29-34.

Source of Support: Nil, Conflict of Interest: None declared.

\section{“QUICK RESPONSE CODE” LINK FOR FULL TEXT ARTICLES}

The journal issue has a unique new feature for reaching to the journal's website without typing a single letter. Each article on its first page has a "Quick Response Code". Using any mobile or other hand-held device with camera and GPRS/other internet source, one can reach to the full text of that particular article on the journal's website. Start a QR-code reading software (see list of free applications from http://tinyurl.com/yzlh2tc) and point the camera to the QR-code printed in the journal. It will automatically take you to the HTML full text of that article. One can also use a desktop or laptop with web camera for similar functionality. See http://tinyurl.com/2bw7fn3 or http://tinyurl.com/3ysr3me for the free applications. 